\title{
An efficacy evaluation of the cognitive intervention services for the aging seniors
}

\author{
Yaqi Zhang ${ }^{1, \text { a }}$ \\ ${ }^{1}$ School of Management Science and Engineering, Central University of Finance and Economics, \\ Beijing 100081, China; \\ atiange93@126.com
}

Keywords: Cognitive intervention; Effectiveness evaluation; Empirical study.

\begin{abstract}
The aging process of the elder people is usually alongside with memory loss, lack of attention and other cognitive decline in performance. This study sets out to find the level of correlation between the elderly people's cognitive ability and the possible sources of decay which include: age, gender, education level, smoking or drinking habits, frequency of exercise, variability of heart rate, mental health and other factors. The cognitive intervention was simulated to measure the possible effect of intervention on the cognitive ability of the elderly. The effectiveness of these cognitive interventions was evaluated during this study. The results showed that the cognitive ability of the elderly was positively related with gender, education years, smoking, drinking and level of mental health for the length of two weeks during the study. Negative correlations were found between the cognitive ability and factors including: age, exercise frequency, and high heart rate variability. Certain improvement over the efficacy of the interventive treatment was found among elderly people with mild cognitive impairment.
\end{abstract}

\section{Introduction}

The world is gradually entering an aging society; the rapid development of the elderly population is bound to be affecting the lives of the elderly themselves, and their families, arising series of new problems within the society. In the process of aging, the cognitive function of the elderly decays evidently. The deteriorated cognitive functions badly influenced the life quality of the elderly people, and even seriously affect their daily lives. Cognitive function is at the core of human brain to understand and reflect on the psychological impressions of objective things, including perception, attention, memory, thinking, language and other capabilities. During the aging process, symptoms of memory loss, inability to concentrate and other cognitive decline within the performance of the elderly or mild cognitive impairment (MCI) has become more prevalent. The incidence of increased Alzheimer, such as Alzheimer Morbidity (Alzheimer's disease, AD) has gradually increased. It is predicted that, 37 million out of 1.1 billion elderly people over the age of 65 will carry with the symptoms of dementia by the year of 2050. [1]

Both the absolute number of elderly people and the speed of aging for the population in China have been at the top of the world, driving the sights of more and more organizations and institutions over to the topic of taking care of invalid senior people. As a pilot project for Beijing's community-based community service for the elderly in the community, the Bei Ke Le Huo Tang (Beijing Municipal Science and Technology Research Institute of the elderly service research team under the community home care service brand) was set up for the elderly people with cognitive decline. This experimental project in Beijing was set up regarding the successful experience of Taiwan, Japan and the United States where concerned organizations have developed series of elderly cognitive impairment intervention activities, including physical fitness, mental gymnastics, cognitive training. However, it is still an urgent problem to evaluate the effectiveness of these cognitive intervention activities and evaluate the service satisfaction of Le Huo Tang.

At the present time, there is no special cure for Alzheimer's disease. In recent years, varied researches abroad have proved cognitive intervention service effective in delaying cognitive decline 
and senile dementia, taking this service as one of the most crucial measures in curing the relative diseases. Prior studies have shown that the cognitive function of the elderly can be improved by training. Training at certain extent can even lead to changes in brain volume and brain activation. This phenomenon is called cognitive plasticity and neural plasticity. In a month's short-term intervention, Noice found that the elderly involved in role-playing training group had their cognitive function and result of psychological testing significantly improved when comparing with the control group [2]. With the help of a randomized examination in 2002 toward 2832 elderly people at the age of 65 to 94 years old, Ball K concluded that specific trainings can significantly improve expected cognitive ability and that the improved capacities are sustainable for the length of 2 to 3 years. A research conducted by Wenisch in evaluating the efficacy of cognitive intervention: 12 MCI (mild cognitive impairment) patients and 12 healthy elderly people were trained through intervention measures including logic memory, word pairing association, connection training and language fluency training. The results showed that the cognitive ability of the two groups of people has significantly improved. The group of MCI patients has witnessed great improvements by the elderly people upon their ability of correlating memorization through cognitive intervention measures [4]. Belleville performed episodic memory training for MCI patients, including list recall, face-name memory strategies, and text memory. The results showed that memory capacity of patients with MCI were significantly improved [5].

Cognitive function assessment is the use of various assessment scales on the patient's perception, attention, memory, language, implementation capacity and other aspects in series of evaluation. There are hundreds of cognitive function assessment scales. According to the content of cognitive function being checked in the scales, they are divided into two genres: individual cognitive function assessment scale and comprehensive cognitive function assessment scale. Compared with the individual cognitive assessment scale, the comprehensive cognitive assessment scale covers a wide range of cognitive function assessment. Respectively, wider range of measurement can be a more comprehensive reflection of cognitive ability. The Mini Mental State Examination (MMSE) was devised to fulfill the comprehensiveness of the evaluation toward intervention measures. In this set of examinations, self-made questionnaires are used to collect the information, and the MMSE scores will be used to represent the cognitive ability of the samples. This score was used as the dependent variable and multiple linear regression was conducted with factors such as age, sex, length of schooling, smoking, alcohol consumption, exercise, heart rate, and feeling in the past two weeks. As the indicator "level of well-being" will change as long as the subjects are exposed to regular outdoor activities, we will use the change of this variable to measure the efficacy of the intervening methods toward the cognitive ability of the elderly people. Evaluation of the cognitive intervention measures was drawn regarding the level of effectiveness extracted through the examination data.

\section{Data and Methodology}

Based on the elderly health status of the follow-up survey data gathered by Peking University, the data simulation for this study was conducted. First of all, the 15,638 data samples in 2005 were divided into six levels according to age, namely, 60-70,70-80,80-90,90-100,100-110,110-120, stratified sampling was utilized to gain the 500 sets of data for the following study. The sampling results are shown in Table 1. Using the statistical function of excel, the data features of each vertical index in the 500 data are analyzed, and 500 new data are simulated to carry out this empirical study. 
Table 1 Result of stratified sampling

\begin{tabular}{c|c|c}
\hline \multicolumn{1}{c}{ Age } & Sum & Age of the sampled subjects \\
\hline $60-70$ & 2031 & $500 \times(2031 / 15638)=65$ \\
$70-80$ & 3249 & $500 \times(3249 / 15638)=104$ \\
$80-90$ & 4230 & $500 \times(4230 / 15638)=135$ \\
$90-100$ & 4050 & $500 \times(4050 / 15638)=129$ \\
$100-110$ & 2056 & $500 \times(2056 / 15638)=66$ \\
$110-120$ & 22 & $500 \times(22 / 15638)=1$ \\
\hline
\end{tabular}

In this study, we used a self-designed questionnaire to collect general demographic information (gender, age, education duration, marital status, etc.), physical condition (blood pressure, heart rate, height, weight, etc.) history of smoking and drinking, frequency of physical exercise and so on. The conditions for all participants of this study were measured in accordance with the Mini Mental State Examination (MMSE) to assess their overall cognitive functionality, respectively, from five major aspects: the general ability, responsiveness, attention and computing power, memory, language, understanding and self-coordination ability. Score scale shown in Table 2, each question answered was labelled as one point across the row, and questions not answered will receive the point of zero, while the responds including "cannot answer" or doubtful element would be labelled as 8. MMSE scores were derived by adding these aforementioned scores altogether. The purpose of this experiment was to evaluate the effectiveness of the cognitive intervention for elderly people whose mental functions had been mildly impaired. When the responds included the ones "cannot answer" or other doubtful elements, this study took it as the sign of more serious cognitive impairment. As these types of responds had nothing to do with the purpose of this study, data that were labelled with the score of 8 were taken as irrelevant with the aim of this study. After data processing, a total of 242 actual samples were obtained. 
Table 2 Mini Mental State Examination for the elderly people

\begin{tabular}{|c|c|c|c|c|}
\hline \multicolumn{2}{|l|}{ Phase } & \multicolumn{3}{|c|}{ Scores } \\
\hline C1. Norms & $\begin{array}{l}\text { * C1-1.What time is it (Morning, forenoon, noon, afternoon, } \\
\text { evening) ? } \\
\text { * C1-2. What month is it (any types of calendar ) ? } \\
\text { * C1-3. What is the date of Mid-autumn festival (any types of } \\
\text { calendar) ? } \\
\text { * C1-4. What is the quarter of the year by now? } \\
\text { * C1-5. Which district are we in? }\end{array}$ & $\begin{array}{l}1 \\
1 \\
1 \\
1\end{array} \mid$ & $\begin{array}{l}0 \\
0 \\
0 \\
0\end{array}$ & $\begin{array}{l}8 \\
8 \\
8 \\
8 \\
8 \\
8\end{array}$ \\
\hline \multicolumn{2}{|r|}{ ( } & \multicolumn{3}{|c|}{ Scores } \\
\hline C2. Reaction & $\begin{array}{l}\text { * C2-1. Please repeat the following words in the same } \\
\text { sequence: table, apple, clothes: } \\
\text { table } \\
\text { apple } \\
\text { clothes }\end{array}$ & $\begin{array}{l}1 \\
1 \\
1\end{array}$ & $\begin{array}{l}0 \\
0 \\
0\end{array}$ & $\begin{array}{l}8 \\
8 \\
8 \\
\end{array}$ \\
\hline \multicolumn{2}{|r|}{ ( } & \multicolumn{3}{|c|}{ Scores } \\
\hline $\begin{array}{l}\text { C3. } \\
\text { Attentiveness }\end{array}$ & \begin{tabular}{|l}
$*$ C3-1. If you hold 20 yuan from the beginning, with a \\
consumption of 3 yuan, how much is left? \\
Remaining money after another 3-yuan consumption? \\
Remaining money after another 3-yuan consumption? \\
Remaining money after another 3-yuan consumption? \\
Remaining money after another 3-yuan consumption? \\
$*$ C3-2. Please draw the figure on the given card
\end{tabular} & $\begin{array}{l}1 \\
1 \\
1 \\
1 \\
1\end{array}$ & $\begin{array}{l}0 \\
0 \\
0 \\
0 \\
0\end{array}$ & $\begin{array}{l}8 \\
8 \\
8 \\
8 \\
8 \\
8\end{array}$ \\
\hline \multicolumn{2}{|l|}{ Phase } & \multicolumn{3}{|c|}{ Scores } \\
\hline C4. Recalling & $\begin{array}{l}{ }^{*} \text { C4- } 1 \text {. Please repeat the three things that were mentioned in } \\
\text { the } 2^{\text {nd }} \text { phase } \\
\text { Table } \\
\text { Apple } \\
\text { Clothes }\end{array}$ & $\begin{array}{l}1 \\
1 \\
1\end{array}$ & $\begin{array}{l}0 \\
0 \\
0\end{array}$ & $\begin{array}{l}8 \\
8 \\
8\end{array}$ \\
\hline \multicolumn{2}{|l|}{ Phase } & \multicolumn{3}{|c|}{ Scores } \\
\hline \multirow[t]{3}{*}{$\begin{array}{l}\text { C5. Language } \\
\text { and } \\
\text { comprehen-si } \\
\text { on }\end{array}$} & $\begin{array}{l}* \text { C5-1. Pointing to a pen and a watch and ask the subjects for } \\
\text { their names ? } \\
\text { Pen } \\
\text { Watch }\end{array}$ & $\begin{array}{l}1 \\
1\end{array}$ & $\begin{array}{l}0 \\
0\end{array}$ & $\begin{array}{l}8 \\
8\end{array}$ \\
\hline & $\begin{array}{l}\text { * C5-2. Please repeat the following words: } \\
\text { Plant the melon at the front door, and grow the beans at the } \\
\text { back }\end{array}$ & 1 & 0 & 8 \\
\hline & $\begin{array}{l}* \text { C5-3. The researcher gives the subjects a piece of paper } \\
\text { Please hold this paper with your right hand, fold it, and put it } \\
\text { on the ground } \\
\text { Holding with right hand } \\
\text { Folding the paper } \\
\text { Putting on the ground }\end{array}$ & $\begin{array}{l}1 \\
1 \\
1\end{array}$ & $\begin{array}{l}0 \\
0 \\
0\end{array}$ & $\begin{array}{l}8 \\
8 \\
8\end{array}$ \\
\hline
\end{tabular}

\section{Empirical Results}

Data extracted from the stratified sampling was analyzed according to varied features and are shown as followed in Table 3. 
Table 3 Features of the MMSE scores before the intervening measures

\begin{tabular}{c|c|ccccc|c}
\hline Age & \multirow{2}{*}{$\begin{array}{c}\text { No. of } \\
\text { subjects }\end{array}$} & $\begin{array}{c}\text { Norms } \\
(5)\end{array}$ & $\begin{array}{c}\text { Reaction } \\
(3)\end{array}$ & $\begin{array}{c}\text { Attentiveness } \\
(6)\end{array}$ & $\begin{array}{c}\text { Recall } \\
(3)\end{array}$ & $\begin{array}{c}\text { Language and } \\
\text { comprehension (6) }\end{array}$ & \\
\hline $\mathbf{6 0 - 7 0}$ & 49 & 4.98 & 2.96 & 5.59 & 2.78 & 6.12 & 22.43 \\
\hline $\mathbf{7 0 - 8 0}$ & 67 & 4.88 & 2.64 & 5.15 & 2.37 & 5.85 & 20.90 \\
\hline $\mathbf{8 0 - 9 0}$ & 70 & 4.90 & 2.69 & 5.30 & 2.26 & 5.49 & 20.63 \\
\hline $\mathbf{9 0 - 1 0 0}$ & 43 & 4.53 & 2.51 & 5.74 & 2.21 & 5.19 & 20.19 \\
\hline $\mathbf{1 0 0 - 1 1 0}$ & 13 & 4.23 & 2.15 & 6.92 & 1.15 & 4.92 & 19.38 \\
\hline
\end{tabular}

The results in Table 4 are plotted on the same line graph as shown in Figure 1. It can be seen from Figure 1, with the growth of age, the general ability of the elderly: ability to respond, recall, master the languages, understanding and self-coordination are declining.

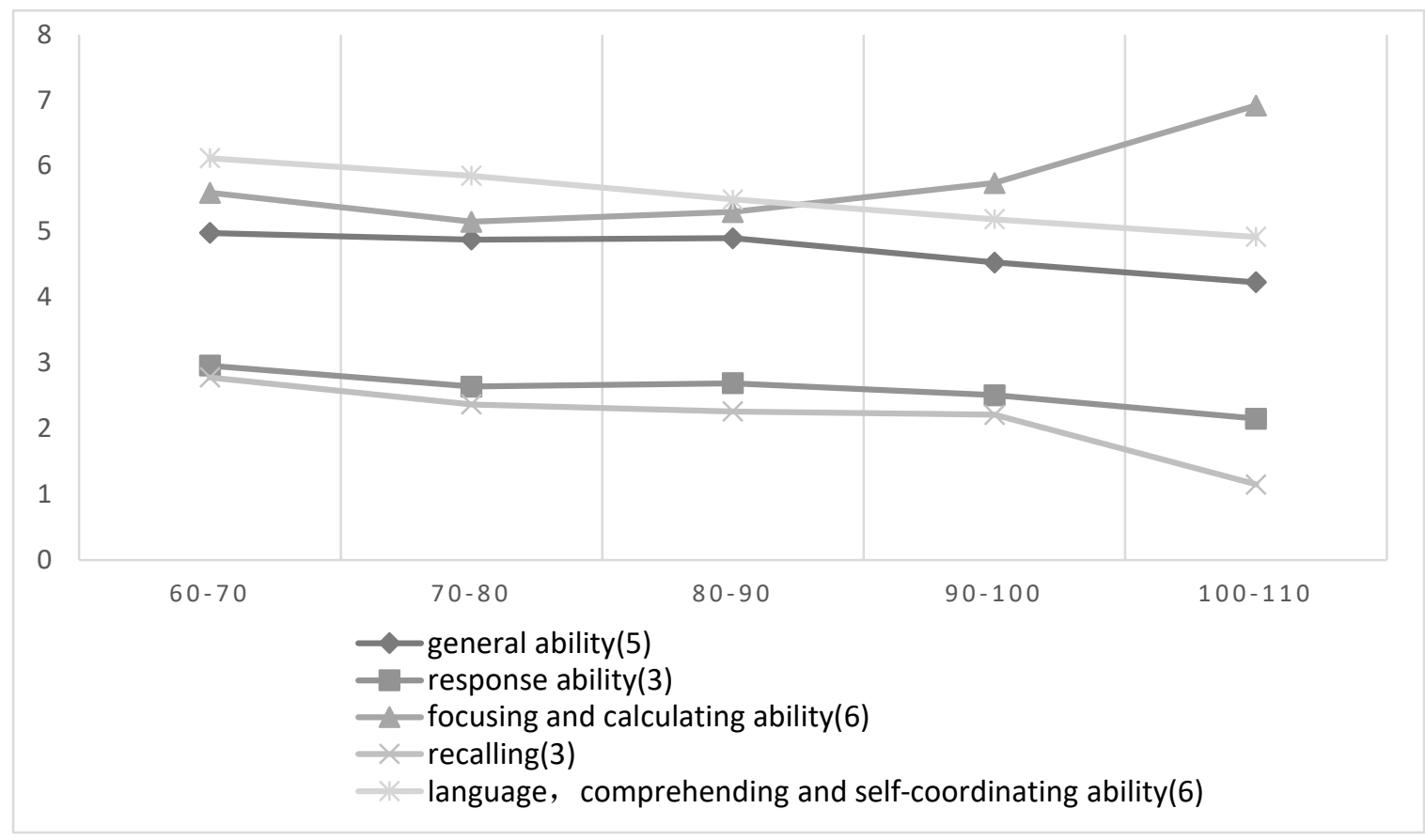

Figure 1 the trend of data before the cognitive intervention

For the evaluation of cognitive ability, the majority of prior studies used MMSE scale score as the standard for the derivation of evaluation results. Based on this, we decided to use the MMSE scores of the study to characterize the sample's cognitive ability. The factors that affect the cognitive ability, such as age, sex, age, smoking, alcohol consumption, exercise, heart rate, and mental wellbeing in the past two weeks are taken as explanatory variables to conduct linear regression. Multivariate linear regression model is shown as Figure 1,

$$
y=\beta_{0}+\beta_{1} x_{1}+\beta_{2} x_{2}+\beta_{3} x_{3}+\ldots+\beta_{k} x_{k}+u
$$

In this case, $\mathrm{y}$ is the explanatory dependent variable, $x_{i}(\mathrm{i}=1,2, \ldots, \mathrm{k})$ is the explanatory variable, $\beta_{i}(\mathrm{i}=1,2, \ldots, \mathrm{k})$ is the regression coefficient, $u$ is the random error term.

Based on the above data, stata software was used to conduct multiple linear regression, the results are shown in Table 4, multiple linear regression equation (shown as Figure 2) is derived to evaluate the cognitive ability.

$$
Y=24.40781-0.0704364 X_{1}+1.56061 X_{2}+0.0059239 X_{3}+0.2013004 X_{4}+0.9128126 X_{5}-0.2291321 X
$$


$6-0.2713159 \mathrm{X}_{7}+1.019393 \mathrm{X}_{8}$

In this model, $\mathrm{Y}$ works as the dependent variable, while $\mathrm{X}_{4}$ (whether or not to smoke), $\mathrm{X}_{5}$ (whether drinking), $\mathrm{X}_{6}$ (whether exercise), $\mathrm{X}_{7}$ (heart rate is the rule), and $\mathrm{X}_{8}$ (Whether the last two weeks feel good) work as independent variable. The MMSE scores were positively correlated with gender, education duration, smoking, drinking and whether they had been feeling good in the past two weeks. There was a significant negative correlation between gender, alcohol consumption and whether they had been feeling good in the past two weeks.

Table 4 the empirical results of multiple regression

\begin{tabular}{r|cccccc}
\hline $\mathrm{Y}$ & Coef. & Std. Err. & $\mathrm{t}$ & $\mathrm{P}>|\mathrm{t}|$ & [95\% Conf. & Interval] \\
\hline $\mathrm{X} 1$ & -0.0704364 & .017043 & -4.13 & 0.000 & -.1040167 & -.0368561 \\
$\mathrm{X} 2$ & 1.56061 & .400605 & 3.90 & 0.000 & .7712857 & 2.349935 \\
$\mathrm{X} 3$ & .0059239 & .0280675 & 0.21 & 0.833 & -.0493784 & .0612262 \\
$\mathrm{X} 4$ & .2013004 & .4609355 & 0.44 & 0.663 & -.7068954 & 1.109496 \\
$\mathrm{X} 5$ & .9128126 & .4642576 & 1.97 & 0.050 & -.0019289 & 1.827554 \\
$\mathrm{X} 6$ & -.2291321 & .3688945 & -0.62 & 0.535 & -.9559766 & .4977125 \\
$\mathrm{X} 7$ & -.2713159 & .6252732 & -0.43 & 0.665 & -1.503312 & .9606798 \\
X8 & 1.019393 & .4459286 & 2.29 & 0.023 & .1407662 & 1.898021 \\
_cons & 24.40781 & 1.550629 & 15.74 & 0.000 & 21.35256 & 27.46307 \\
\hline
\end{tabular}

It is obvious that the indicator of whether "the past two weeks are feeling good" will change after the intervention of the sample subjects. Therefore, we will use this indicator to measure the amount of change in intervention for cognitive function of the elderly intervention effect. In order to get more scientific and objective data, the team members use excel random number generator, the data for each age indicator of the index. We assume that "the past two weeks feel good" this indicator obeys Bernoulli distribution. "Feel good in the past two weeks" is counted as 1; "Feeling bad in the past two weeks" is counted as zero. Let p be the probability that "the past two weeks are feeling good". With intervention, $p$ will increase. To ensure the accuracy of the experiment, we stratified the $p$ values of different age ranges and increased by 0.1 . According to the known multiple linear regression equation, the MMSE score of the elderly after intervention was scored as $\mathrm{Y}^{*}$ and the scores $\mathrm{Y}$ and MMSE actual scores obtained by multiple linear regression without intervention were compared. The results are shown in Tables 5 and Figure 2 shows. Figure 2 shows, with age, MMSE score, Y was decreasing trend, consistent with the actual. The intervention increased $\mathrm{Y}$ to $\mathrm{Y}{ }^{*}$, indicating that intervention could improve the cognitive ability of the elderly.

Table 5 The comparison between the scores with and without cognitive intervention

\begin{tabular}{cccc}
\hline Age & MMSE & $\mathbf{Y}$ & $\mathbf{Y}^{*}$ \\
\hline $\mathbf{6 0 - 7 0}$ & 22.4167 & 21.8422 & 21.9956 \\
\hline $\mathbf{7 0 - 8 0}$ & 20.8955 & 21.3231 & 21.4296 \\
\hline $\mathbf{8 0 - 9 0}$ & 20.6286 & 20.6971 & 20.799 \\
\hline $\mathbf{9 0 - 1 0 0}$ & 20.1905 & 20.1899 & 20.2869 \\
\hline $\mathbf{1 0 0 - 1 1 0}$ & 19.6667 & 19.1607 & 19.3306
\end{tabular}




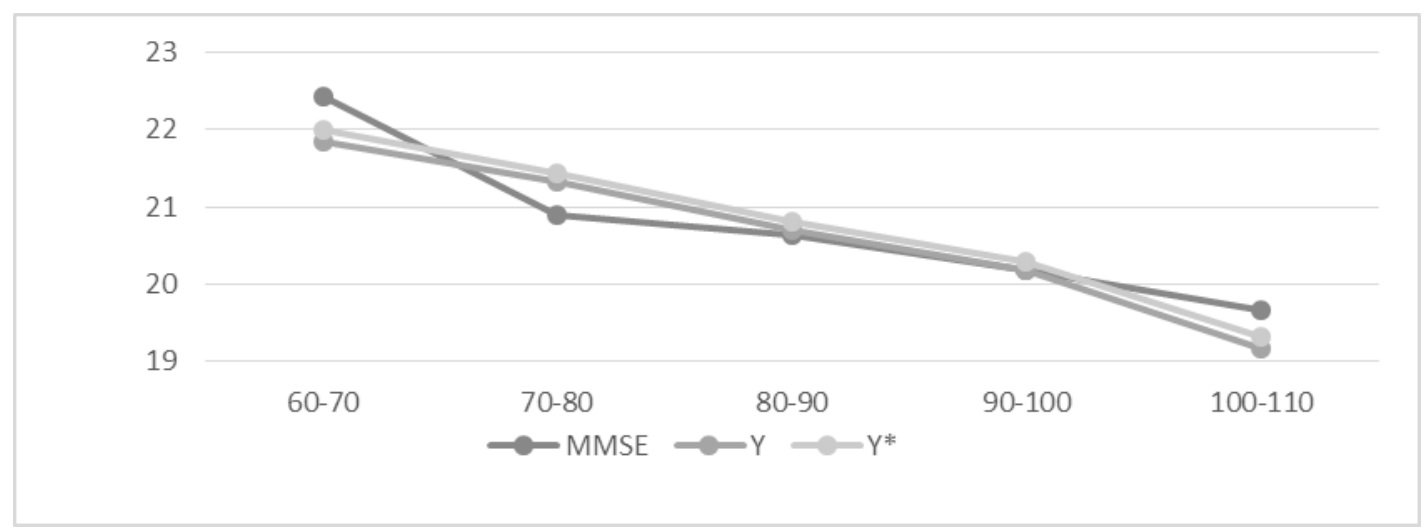

Figure 2 the trend of change for the scores

\section{Conclusions}

In this paper, we test the cognitive ability of the elderly; explore the factors which affect the cognitive ability including age, sex, education, smoking, alcohol using, exercising, heart rate, the last two weeks' feelings and other factors etc.; evaluate the effectiveness of the intervening measures on the cognitive ability of the elderly, and evaluate the effectiveness of the intervention. The results show that the cognition of the elderly was negatively correlated with gender, education duration, smoking, drinking and the other factors mentioned above. People with mild cognitive impairment have a certain improvement in cognitive capacity. In order to benefit the elderly of all ages, more specific intervening measures should be the focal point of future research to improve the quality of life of the elderly people.

\section{References}

[1] Gavrilov, L. A., \& Heuveline, P. (2003). Aging of population. The encyclopedia of population, 1, 32-37.

[2] Noice, H., Noice, T., \& Staines, G. (2004). A short-term intervention to enhance cognitive and affective functioning in older adults. Journal of aging and health,16(4), 562-585.

[3] Ball, K., Berch, D. B., Helmers, K. F., Jobe, J. B., Leveck, M. D., Marsiske, M., ... \& Unverzagt, F. W. (2002). Effects of cognitive training interventions with older adults: a randomized controlled trial. Jama, 288(18), 2271-2281.

[4] Wenisch, E., Cantegreil-Kallen, I., De Rotrou, J., Garrigue, P., Moulin, F., Batouche, F., ... \& Rigaud, A. S. (2007). Cognitive stimulation intervention for elders with mild cognitive impairment compared with normal aged subjects: preliminary results. Aging Clinical and Experimental Research, 19(4), 316-322.

[5] Belleville, S., Gilbert, B., Fontaine, F., Gagnon, L., Ménard, É., \& Gauthier, S. (2006). Improvement of episodic memory in persons with mild cognitive impairment and healthy older adults: evidence from a cognitive intervention program. Dementia and geriatric cognitive disorders, 22(5-6), 486-499. 